\title{
Novel variants in the ACTA2 and MYH11 genes in a Cypriot family with thoracic aortic aneurysms: a case report
}

\author{
Anna Keravnou ${ }^{1,2^{*}}$, Evy Bashiardes ${ }^{1,2}$, Kyriaki Michailidou ${ }^{2,3}$, Marinos Soteriou ${ }^{4}$, Areti Moushi ${ }^{2}$ and Marios Cariolou ${ }^{1,2^{*}}$ (D)
}

\begin{abstract}
Background: Thoracic aortic aneurysm (TAA) and/or thoracic aortic aneurysm and dissection (TAAD) is characterized by a considerable risk of morbidity and mortality of affected individuals. It is inherited in an autosomal dominant pattern and the $20 \%$ of patients with non-syndromic TAA have a positive family history. To date, the genetic basis of Cypriot patients with TAA has not been investigated. The purpose of this case report is to determine underlying genetic cause in this Cypriot family with TAA.

Case presentation: In this report we present a patient with hyper-acute onset chest and back pain diagnosed with Type A Aortic Dissection with severe aortic valve regurgitation, who underwent emergency aortic surgery and Bentall procedure. Further investigation of the patient's family was undertaken where both parents and an additional child were also found to be affected. A targeted sequencing panel including genes with known association to TAA was used to identify causative mutations in the index patient. Massively Parallel Sequencing results identified a frameshift deletion c.363_367del GAGTC, p.Met121llefs*5 in the ACTA2 gene and a non-synonymous variant c.3234C > G, p.lle1078Met in the MYH11 gene. The presence or absence of these variants in the index patient and other family members was verified by Sanger sequencing. To our knowledge, this is the first report of a Cypriot family case diagnosed with TAA presented by two novel variants one in the ACTA2 and the other in the MYH11 genes.
\end{abstract}

Conclusions: We describe two novel variants in a Cypriot family with TAA that are potentially pathogenic, highlighting the importance of molecular genetic evaluation in families with TAA. These results may prove useful for screening purposes in Cypriot patients with non-syndromic familial TAA facilitating early identification of atrisk family members and direct intervention.

Keywords: Aortic aneurysm, ACTA2, MYH11, Cyprus, Targeted next generation sequencing

\section{Background}

Thoracic aortic aneurysms (TAAs) and dissection (TAAD) is an aortopathy that can cause aortic rupture which is associated with a considerable risk of morbidity and mortality. TAA is a complex, heterogeneous and often lethal disease that predominantly displays an autosomal dominant pattern of inheritance $[1,2]$. The majority of the patients $(95 \%)$ do not have any symptoms until a major event occurs, such as aortic dissection or rupture [3-5]. It may be classified as syndromic or non-syndromic, including familial TAA. It is estimated that approximately $20 \%$ of

\footnotetext{
*Correspondence: annak@cing.ac.cy; cariolou@cing.ac.cy

${ }^{1}$ Department of Cardiovascular Genetics and The Laboratory of Forensic Genetics, The Cyprus Institute of Neurology and Genetics, Nicosia, Cyprus Full list of author information is available at the end of the article
}

patients with non-syndromic TAA have a positive family history [3]. Familial studies showed that there is a 10 -fold increased incident rate in first-degree relatives with a family history of TAA. Therefore, screening of first-degree relatives should be introduced as part of clinical practice [6].

With recent advances in Massively Parallel Sequencing (MPS), new variants associated with TAA clinical phenotype have been identified that relate to the clinical phenotype [7-9]. To date, 30 causative genes (Additional file 1) [10] that contribute to the development of TAA have been identified with the majority being related to genes encoding proteins involved in the smooth muscle cell contractile apparatus (e.g. ACTA2, MYH11, MYLK, and PRKG1), extracellular matrix (e.g. $F B N 1$ ), or the transforming growth factor $-\beta$ signaling pathway (e.g. TGFB2, TGFBR1,

(c) The Author(s). 2018 Open Access This article is distributed under the terms of the Creative Commons Attribution 4.0 International License (http://creativecommons.org/licenses/by/4.0/), which permits unrestricted use, distribution, and 
TGFBR2, and SMAD3). Therefore, the identification of novel variants in genes associated with TAA is considered an area of progress that may lead to earlier detection and treatment of the disease [11, 12].

In the current study our aim was to identify any possible genetic cause, for the first time, in a Cypriot familial case of TAA in which two parents and the two children were affected. When preparing this case report the CARE Guidelines: Consensus-based Clinical Case Reporting Guideline Development were taken into account [13].

\section{Case presentation}

The study was approved by the Cyprus National Bioethics Committee and informed, written consent was obtained from all participants.

The patient under discussion is a 30 year old male, weight lifter with hyper-acute onset chest and back pain. Upon initial evaluation, the patient did not have any manifestation of any phenotypic findings (i.e. iris flocculi, livedo reticularis, aortic valve abnormalities) hinting towards connective tissue disorders or aortic pathology. Based on echocardiography and chest $\mathrm{CT}$ findings the patient was diagnosed with a Type A Aortic Dissection with severe aortic valve regurgitation. The patient was then emergently intubated and was transferred to the American Medical Center (AMC) in Nicosia, Cyprus where he had emergency aortic surgery and Bentall procedure. No angiography was performed due to the fact that the patient had aortic dissection and was an emergency. Intraoperative findings showed a $70 \mathrm{~mm}$ diameter aortic root aneurysm with dissection extending from the sinotubular junction to the aortic root. The aortic annulus was extensively dilated and the aortic dissection extended down the origin of the left main coronary artery involving also the aortic valve commissures that resulted in severe aortic valve regurgitation. There was no evidence of involvement of the distal ascending aorta and the aortic arch.

Further evaluation of the patient's family showed that several family members had ascending aortic aneurysms. The patient's father, a 60-year-old male had an asymptomatic aortic root and ascending aortic aneurysm of $52 \mathrm{~mm}$ that also required aortic valve, aortic root and ascending aortic replacement (Bentall procedure). Pre-operatively thefather had CT chest coronary angiography that confirmed the presence and dimensions of the aneurysm and coronary angiography did not show any coronary artery disease. The patient's mother, a 56-year-old female was also screened with echocardiography that showed ascending aortic dilatation, $42 \mathrm{~mm}$ in diameter. Subsequent screening of the siblings, two sisters at the ages of 22 and 34 respectively did not show any abnormalities. Following the genetic screening of the index patient, his parents and his siblings, a follow-up was recommended for both his sisters. Six years after the initial screening of the sisters, the 34-year-old was found to have a mild dilation of the ascending aorta $(39 \mathrm{~mm}$ ) by echocardiography with a $4-5 \mathrm{~mm}$ increase in diameter in comparison with the previous echocardiography results. The pedigree of the family is demonstrated in Fig. 1. The index patient's and the family's medical diagnosis and interventions are shown in Table 1.

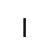

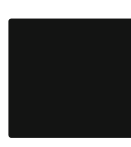
66 yo MYH11 (C>G)
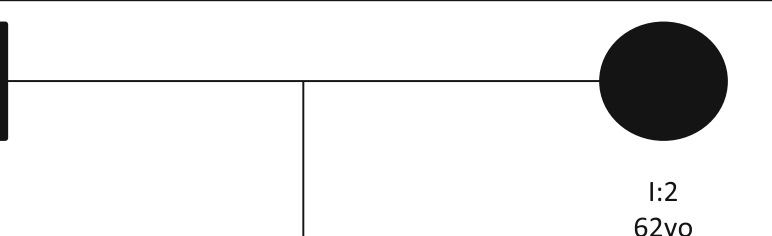

II

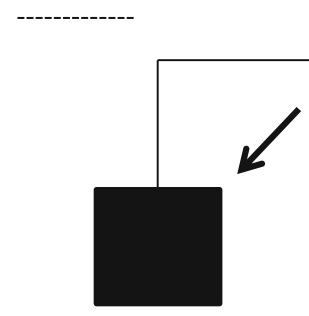

II:1

43 yo

MYH11 (C>G)

ACTA2 (delGAGTC)

ACTA2 (delGAGTC)
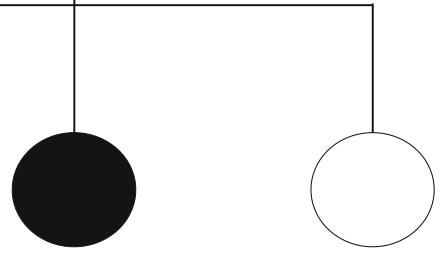

II:3

35 yo

ACTA2 (delGAGTC)

Fig. 1 Pedigree of the family with c.3234C > G, p.lle1078Met variant in MYH11 gene and c.363_367del GAGTC, p.Met121llefs*5 variant in ACTA2 gene. The individual II:2 on initial screening had normal aortic measurements and after genetic screening was re-evaluated and found to have a mild dilation. Proband is indicated with an arrow; Black-filled symbols represent affected individuals with TAA; Age of the family members and their genotypes are listed below the symbols; Dotted lines indicate the absence of the mutation 
Table 1 The index patient's and the family's medical diagnosis and interventions

\begin{tabular}{|c|c|c|c|c|c|}
\hline \multirow[b]{3}{*}{ Dates } & \multicolumn{5}{|c|}{ Relevant Past Medical History and Interventions } \\
\hline & \multicolumn{5}{|c|}{ No past medical history reported by the index patient whose symptoms and diagnosis were initiated in 2005} \\
\hline & Study Project & Sequence Variants & $\begin{array}{l}\text { Summaries from Initial } \\
\text { and Follow-up Visits }\end{array}$ & Diagnostic Testing & Interventions \\
\hline 2005 & Index patient & $\begin{array}{l}\text { MYH11:c.3234C > G, p.lle1078Met } \\
\text { ACTA2:c.363_367delGAGTC, } \\
\text { p.Met121llefs*5 }\end{array}$ & $\begin{array}{l}\text { Hyper-acute onset chest } \\
\text { and back pain }\end{array}$ & $\begin{array}{l}\text { Echocardiography and } \\
\text { CT Chest }\end{array}$ & Bentall procedure \\
\hline 2016 & & & Follow-up visit & Echocardiogram & $\begin{array}{l}\text { No further intervention as } \\
\text { no significant change found }\end{array}$ \\
\hline 2017 & & & Counseling visit & Genetic testing & $\begin{array}{l}\text { Novel variants detected in } \\
\text { ACTA2 and MYH11 genes }\end{array}$ \\
\hline 2012 & Father & MYH11:c.3234C > G, p.lle1078Met & Asymptomatic & $\begin{array}{l}\text { Echocardiography and } \mathrm{CT} \\
\text { Chest coronary angiography }\end{array}$ & Bentall procedure \\
\hline 2015 & & & Follow-up visit & $\begin{array}{l}\text { Henoch-Schonlein purpura in } \\
\text { low extremities, Kidney failure }\end{array}$ & Hemodialysis \\
\hline 2017 & & & Follow-up visit & Echocardiogram & $\begin{array}{l}\text { No further intervention } \\
\text { recommended }\end{array}$ \\
\hline 2017 & & & Counseling visit & Genetic testing & $\begin{array}{l}\text { Novel variant detected in } \\
\text { MYH11 gene }\end{array}$ \\
\hline 2012 & Mother & $\begin{array}{l}\text { ACTA2:C.363_367delGAGTC, } \\
\text { p.Met121llefs*5 }\end{array}$ & Asymptomatic & Echocardiogram & Ascending aortic dilatation \\
\hline 2015 & & & Follow-up visit & Echocardiogram & No significant change found \\
\hline 2017 & & & Counseling visit & Genetic testing & $\begin{array}{l}\text { Novel variant detected in } \\
\text { ACTA2 gene }\end{array}$ \\
\hline 2005 & Sister \#1 & $\begin{array}{l}\text { MYH11:c.3234C > G, p.lle1078Met } \\
\text { ACTA2:c.363_367delGAGTC, } \\
\text { p.Met121llefs*5 }\end{array}$ & Asymptomatic & Echocardiogram & Normal aortic size \\
\hline 2012 & & & Follow-up visit & Echocardiogram & Normal aortic size \\
\hline 2017 & & & Counseling visit & Genetic testing & $\begin{array}{l}\text { Novel variants detected in } \\
\text { ACTA2 and MYH11 genes }\end{array}$ \\
\hline 2017 & & & Follow-up visit & Echocardiography & $\begin{array}{l}\text { Mild dilation of the ascending } \\
\text { aorta }\end{array}$ \\
\hline 2005 & Sister \#2 & & Asymptomatic & Echocardiogram & Normal aortic size \\
\hline 2012 & & & Follow-up visit & Echocardiogram & Normal aortic size \\
\hline 2017 & & & Counseling visit & Genetic testing & $\begin{array}{l}\text { No novel variants detected } \\
\text { in ACTA2 and } M Y H 11 \text { genes }\end{array}$ \\
\hline
\end{tabular}

To understand any genetic implication in the cause of TAA of this family, targeted sequencing was performed on DNA samples from the father and the son. Whole blood samples were used to extract DNA using the QIAamp Blood Midi Kit (Qiagen, Hilden, Germany) according to the manufacturer's instructions.

The TruSight Cardio Sequencing panel (Illumina, San Diego, CA, USA) which includes 16 genes, the most predominant, with known association to familial aortic aneurysm was initially used and paired-end sequencing was performed on an Illumina Miseq platform at our Institute. Our results showed that the two samples (son and father) had an average depth of coverage of $117 x$ and $108 x$ respectively for the $M Y H 11$ region and an average depth of coverage of $135 \mathrm{x}$ and $125 \mathrm{x}$ for the ACTA2. Raw variants were filtered to include only those variants with a coverage depth greater than $20 \times$ and a Quality score greater than 30 . The Illumina run generated $94.8 \%$ of base calls having $>$ Q30 We followed the Genome Analysis Toolkit (GATK) best practices for variant calling. Sequencing reads were aligned to the human reference genome build GRCh37/hg19 using Burrows Wheeler Aligner (BWA) software. Different GATK programs were used for local realignment and base recalibration and the SAMtools (Sequence Alignment/Map) pipeline was used to retrieve per-base read depth information. Calling was performed using Haplotype Caller from the GATK. The called Small Nucleotide Variants (SNVs) and Insertions and Deletions (InDels) were annotated using the Annotate Variation (ANNOVAR) [14] software. The variants were then filtered using the GATK best practices (https://software.broadinstitute.org/gatk/), focusing on rare 
(minor allele frequency $<0.05)$ and known pathogenic variants. MPS results identified a frameshift deletion c.363_367del GAGTC, p.Met121Ilefs"5 in the ACTA2 gene (Genbank transcript ID: NM 001613) and a nonsynonymous variant c.3234C $>$ G, p.Ile1078Met in the MYH11 gene (Genbank transcript ID: NM 001040114). In order to predict the pathogenicity of the novel variants, the in silico software of the computational algorithms SIFT (Sorting Intolerant from Tolerant) [15] (http:// sift.jcvi.org), PolyPhen2 (Polymorphism Phenotyping) [16] (http://genetics.bwh.harvard.edu/pph2), Mutation Taster [17] (http://www.mutationtaster.org), PROVEAN (Protein Variation Effect Analyzer) [18] (http://provean.jcvi.org) and VEP (Variant Effect Predictor) [19] (https://asia.ensembl.org/Tools/VEP) were used. All five different prediction tools (SIFT: Deleterious PolyPhen2: Probably Damaging, Mutation Taster: Disease causing, PROVEAN: Deleterious, VEP: High) presented a consistent result describing the p.Met121Ilefs"5 (c.363_367delGAGTC) variant as having a detrimental/deleterious effect. These predictions, suggest that this variant has a significant effect on the function of ACTA2 and the development of TAA. Regarding the p.IIe1078Met (c.3234C > G) variant in the MYH11 gene, PolyPhen2 and PROVEAN prediction tools presented it as being a benign and neutral variant respectively while, VEP, SIFT and Mutation Taster suggested it as being a moderate, deleterious and disease causing variant respectively In addition, Iterative Threading ASSEmbly Refinement (I-TASSER) modeling [20-22], a protein structure prediction tool, was used to predict the secondary structure of the ACTA2 and MYH11 proteins. The results showed the presence of the amino acids Met121 and Ile1078 respectively, on a helix structure motif (Fig. 2). It is difficult to describe the protein function of the regions where these variants occur as the protein structure of ACTA2 and MYH11 is not completely known as yet after performing a search in UniProtKB and Protein Data Bank (PDB).

It is noteworthy that no known pathological sequence variants were identified in the affected individuals we studied. The TruSight Cardio sequencing panel led to the identification of a $5 \mathrm{bp}$ frameshift deletion in the ACTA2 gene (c.363_367del, p.Met121Ilefs"5) which results in a premature stop codon as well as a non-synonymous variant in the MYH11 gene (c.3234C > G:p.I1078M) predicted as deleterious and disease causing by the in silico software of the computational algorithms used. Both variants were absent from public variant databases, such as the dbSNP (http://www.ncbi.nlm.nih.gov/SNP/), 1000 genome dataset (http://browser.1000 genomes.org/index.html), Genome Aggregation Database (http://gnomad.broadinstitute.org), and Human Genetic Variation Browser (http://www.hgvd.genome.med.kyoto-u.ac.jp/) databases. With respect to the MYH11 (c.3234C > G:p.I1078M) it is noteworthy that (c.3234C > T:p.I1078I) has been detected four times in the Genome Aggregation Database (GnomAD) and it is however synonymous (GnomAD, $n=282,728$ ). Both the affected father and son displayed the novel heterozygous p.Ile1078Met variant in the MYH11 gene while the son was also identified with the novel heterozygous p.Met121Ilefs*5 (c.363_367delGAGTC) variant in the ACTA2 gene.

The identified variants were verified in the proband and other consenting family members (father, mother and two sisters) were screened by Sanger sequencing. PCR amplification was performed using 5 Units AmpliTaq DNA

\begin{tabular}{|c|c|c|c|c|c|c|c|c|c|c|c|c|c|c|c|c|}
\hline $\begin{array}{c}\text { Amino Acid } \\
\text { Position }\end{array}$ & 119 & 120 & 121 & 122 & 123 & 124 & 125 & 126 & 127 & 128 & 129 & 130 & 131 & 132 & 133 & 134 \\
\hline $\begin{array}{l}\text { Amino Acid } \\
\text { Sequence }\end{array}$ & E & $\mathrm{K}$ & M & T & Q & 1 & M & $\mathrm{F}$ & $\mathrm{E}$ & T & $\mathrm{F}$ & $\mathrm{N}$ & v & P & A & M \\
\hline Prediction & $\mathrm{H}$ & $\mathrm{H}$ & H & $\mathrm{H}$ & $\mathrm{H}$ & $\mathrm{H}$ & $\mathrm{H}$ & $\mathrm{H}$ & $\mathrm{H}$ & c & c & c & c & c & s & s \\
\hline $\begin{array}{l}\text { b Amino Acid } \\
\text { Position }\end{array}$ & 1068 & 1069 & 1070 & 1071 & 1072 & 1073 & 1074 & 1075 & 1076 & 1077 & 1078 & 1079 & 1080 & 1081 & 1082 & 1083 \\
\hline $\begin{array}{l}\text { Amino Acid } \\
\text { Sequence }\end{array}$ & E & G & D & A & s & D & $\mathrm{F}$ & $\mathrm{H}$ & $\mathrm{E}$ & $\mathrm{Q}$ & I & A & D & L & Q & A \\
\hline Prediction & H & $\mathrm{H}$ & $\mathrm{H}$ & $\mathrm{H}$ & $\mathrm{H}$ & H & $\mathrm{H}$ & $\mathrm{H}$ & H & $\mathrm{H}$ & H & $\mathrm{H}$ & $\mathrm{H}$ & $\mathrm{H}$ & $\mathrm{H}$ & $\mathrm{H}$ \\
\hline
\end{tabular}

Fig. 2 The predicted secondary structure of $\mathbf{a}$. ACTA2 and $\mathbf{b}$. MYH11 proteins indicating, the location of the amino acids Met121 (bold) and lle1078 (bold) respectively, on a helix structure where the variants (p.Met121llefs*5) and (p.lle1078Met) occur using I-TASSER modeling 
polymerase (Applied Biosystems, Foster City, CS). The ACTA2 gene was initially amplified by PCR at $55^{\circ} \mathrm{C}$ annealing temperature using the ACTA2-Forward: 5' CTTTCAAGCTGTTCCTGTC 3' and the ACTA2-Reverse: 5' TGTGTTTCTCCTCTGTCC 3' primers. The MYH11 gene was amplified by PCR at $55^{\circ} \mathrm{C}$ annealing temperature using the MYH11-Forward: 5' AGTGAACA GGGTCGAGAAG 3' and the MYH11-Reverse: 5' TTTG CAGTGCGGCTAAAG 3' primers. Amplified products were cleaned using QIAquick PCR Purification Kit (Qiagen, Hilden, Germany) and subjected to cycle sequencing according to the manufacturer's instructions [BigDye Terminator v1.1 Cycle Sequencing Kit (Applied Biosystems]. The reactions were run on a $3130 x \mathrm{~L}$ Genetic Analyzer (Applied Biosystems, Foster City, CA, USA) with the results analyzed via the Sequencing Analysis 5.2 Software (Applied Biosystems).

Sanger sequencing analysis of the patients' $A C T A 2$ and MYH11 genes revealed that the p.IIe1078Met variant was inherited from the father and the p.Met121Ilefs*5 variant from the mother (Fig. 3). Results showed that the mother, the son and the 34-yo daughter had the p.Met121Ilefs* 5 variant whereas the father, the son and the same daughter had the p.Ille1078Met variant. Overall, results showed that the affected son and the one daughter are carriers of both variants inherited one from each parent. The second daughter did not show any variants in either of the two genes.

In order to evaluate evidence for a sequence variant we followed the guidelines of the American College of Medical Genetics and Genomics (ACMG) [23]. The two variants (chr10:90703556_90703560delGAGTC and chr16:15831386 G > C) of ACTA2 and MYH11 genes are a deletion which results in a truncated transcript in exon 4 (c.363_367del GAGTC, p.Met121Ilefs*5) and a single base substitution in exon 26 (c.3234C > G, p.Ile1078Met), respectively. Combining the PVS1 criterion (predicted as a null variant) with 1 Moderate (PM2: Absence in population databases) classifies the ACTA2 variant as "likely pathogenic". The MYH11 variant was interpreted as "variant of uncertain significance (VUS)" based on the following criteria: Absent in population databases (PM2), and computational evidence by different in silico tools applied supported a deleterious effect on the gene (PP3). For the p.Ile1078Met of MYH11, the small number of affected individuals (meiosis) was not enough to use the PP1

a C T TRHKTYMTYYYSKYYGGSCTGGSE GTGS 150 160
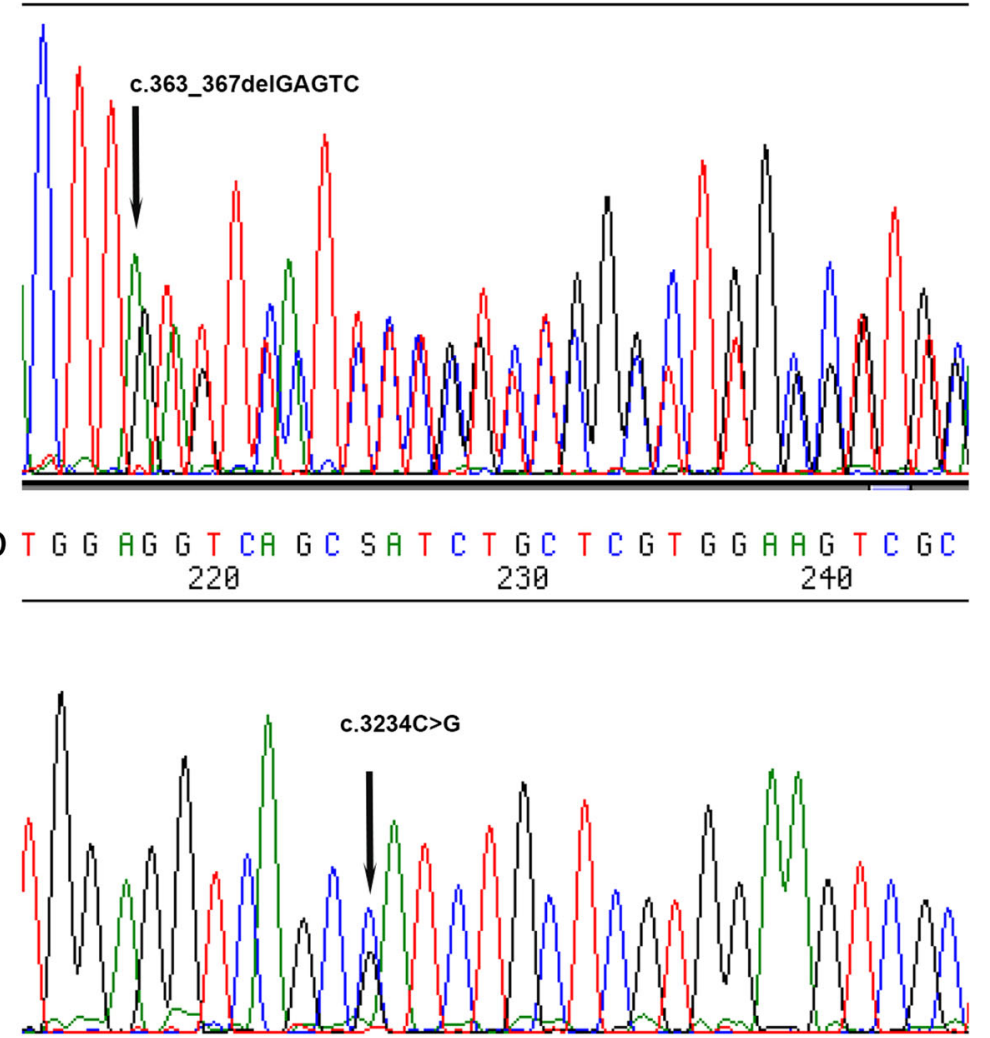

Fig. 3 Representative Sanger sequencing of PCR products showing the index patient with the biallelic variants in a. ACTA2 gene (c.363_367delGAGTC, p.Met121Ilefs*5) and b. MYH11 gene (c.3234C > G, p.lle1078Met) 
criteria. Although this variant is not found in GnomAD controls and is located on coiled-coil myosin heavy chain tail region, the evidence at this point is not enough to indicate that p.Ile1078Met is pathogenic according to ACMG standards. Therefore, we concluded that the variant in ACTA2 is more likely to contribute to the TAA phenotype.

\section{Discussion and conclusions}

TAAD is a potentially lethal disease and it is important to identify individuals who are at risk that can benefit from extensive surveillance and potentially undergo prophylactic treatment. Over the last decades with the implementation of MPS the understanding of gene mutations associated to TAA has greatly improved. As a result, it is expected that a higher number of genes and definitive pathogenic variants will be identified in the following years which will enable further investigation of the pathways that contribute to the onset of disease [24].

To the best of our knowledge this is the first report of a Cypriot family with non-syndromic familial TAA presented with two novel variants in MYH11 and ACTA2 genes. Previous studies reported that pathogenic sequence variants in MYH11 (myosin heavy chain 11) and ACTA2 (smooth muscle cytoskeletal protein actin alpha $(\alpha)-2)$ genes provide direct changes in contractile apparatus of aortic smooth muscle cells (SMC) which cause non-syndromic familial TAAD $[1,25]$. Heterozygous mutations in ACTA2 interfere towards the ability of arteries to stretch resulting in familial TAAD [1, 25-28]. Missense mutations in ACTA2 gene account for the majority of familial TAADs and are responsible for $14 \%$ of non-syndromic TAAD [26, 29]. Mutations in MYH11 gene result in the decrease of the elasticity of the aortic wall which is associated with familial TAAD [30]. Mutations in $M Y H 11$ gene have also been associated with patent ductus arteriosus, one of the most common congenital cardiovascular malformations [30-32]. Pathogenic variants in $\mathrm{MYH11}$ gene are responsible for approximately $1 \%$ of heritable thoracic aortic disease [29].

In the current study, two novel variants were identified. Further in silico analysis, predicted that the novel p.Met121Ilefs*5 (c.363_367delGAGTC) and p.I1078M (c.C3231G:p.I1078M) variants in ACTA2 and MYH11 genes respectively, interfere with protein function and were characterized as possibly disease-causing variants. It was further predicted that the variant c.363_367del would have a more deleterious effect and hence be considered causative due to the introduction of a premature termination codon that would lead to nonsense-mediated mRNA decay. Pathogenic variants in adjacent amino acid residues in exon 4 of ACTA2 gene (N115 T, R116Q, N117S, N117I, $\mathrm{R} 118 \mathrm{Q})$ have been previously reported in families with TAAD which lie within the hydrophobic cleft of a-actin which acts as the binding determinant of several regulatory proteins and is thought to have a key role in actin polymerization [33-36]. These variants including Met121 occurred in evolutionarily, highly conserved amino acid residues (data not shown) which are more likely to contain pathogenic variants (UniProt sequence alignment tool against the genome of six species human/chimpanzee/ mouse/rabbit/chicken/fish). The R118Q variant lies within the hydrophobic cleft of a-actin which acts as the binding site of several regulatory proteins [33]. The presence of p.Met121Ilefs*5 variant was also identified in both mother and sister of the affected son. The identification of the p.Met121Ilefs*5 variant in the apparently normal, non-symptomatic daughter, led to the recommendation of a follow-up, where a mild dilation of the ascending aorta with 4-5 $\mathrm{mm}$ increase in diameter was observed.

The non-synonymous substitution c.3234C > G might lead to changes in the protein function, concluding that this variant is likely responsible for causing the TAA phenotype. The p.Ile1078Met variant in MYH11 was also identified in evolutionarily, highly conserved amino acid residues which is more likely to contain pathogenic variants. The affected son was heterozygous for the p.Ile1078Met (c.3234C > G) variant which was also observed in the affected father and sister. The p.Ile1071Met variant was inherited from the father and the p.Met121Ilefs* 5 variant was inherited from the mother.

Phenotype considerably varies among carriers of mutations in genes associated to TAA and familial occurrence of aortic dissections should always be investigated [37]. Therefore, there is a need for further genetic studies in cases of non-syndromic familial aneurysms so that patients with previous negative or inconclusive results on the diagnostic echo test may benefit from re-testing while avoiding unnecessary concerns in the non-carriers. This proof of principle theory has been demonstrated in our case report. The genetic investigation began with the affected son referred to our Institute. To the best of our knowledge, this is the first report of a familial TAAD case with presenting two novel variants, p.Met121Ilefs*5 and p.Ile1078Met in ACTA2 and MYH11 genes respectively. However, for the verification of these variants and their contribution in the development of TAA, further testing on additional samples from affected individuals is necessary. By looking at the family pedigree, from the father's side, relatives have been contacted by the clinician and informed of the study undertaken and asked to contact the AMC at their convenience to have an assessment as well as to provide a blood sample. These will be used to screen for the p.Ile1078Met variant in MYH11 gene in order to indicate the presence of an association with TAA. So far, the family has not communicated with the AMC. The heterozygous p.Ile1078Met variant in MYH11 gene is a potentially disease-causing variant thus, further studies are needed to elucidate its role in pathogenicity. A limitation of 
this study is the absence of functional assay of the two identified variants to provide their functional relevance in TAA. Another limitation is that the study focused on the most prevalent genes that are related to TAA since these were included in the selected sequencing gene panel. Future investigations on whole exome sequencing could determine the spectrum of genetic variation and mutations associated with non-syndromic familial TAA in Cypriot patients.

In conclusion, we describe a Cypriot familial case with TAA. The screening process for the identification of further mutations and variants, in addition to the two novel variants in the ACTA 2 and $M Y H 11$ genes identified in this report is ongoing. These results will provide a powerful tool for the early identification of non-syndromic familial TAAD patients in order to prevent devastating events by increasing the early screening and prophylactic treatments of affected family members.

\section{Additional file}

Additional file 1: Genes associated with the development of TAAD

(PDF $264 \mathrm{~kb}$ )

\section{Abbreviations}

ACMG: American College of Medical Genetics and Genomics;

ACTA2: Smooth muscle cytoskeletal protein actin alpha(a)-2; AMC: American Medical Center; ANNOVAR: Annotate Variation; BWA: Burrows Wheeler Aligner; CT: Computed tomography; GATK: Genome Analysis Toolkit; GnomAD: Genome Aggregation Database; InDels: Insertions and Deletions; ITASSER: Iterative Threading ASSEmbly Refinement; MPS: Massively Parallel Sequencing; MYH11: Myosin heavy chain 11; PDB: Protein Data Bank; PolyPhen2: Polymorphism Phenotyping; PROVEAN: Protein Variation Effect Analyzer; SAM: Sequence Alignment/Map; SIFT: Sorting Intolerant from Tolerant; SMC: Smooth muscle cells; SNV: Small Nucleotide Variants; TAA: Thoracic aortic aneurysm; TAAD: Thoracic aortic aneurysm and dissection; VEP: Variant Effect Predictor; VUS: Variant of Uncertain Significance

\section{Acknowledgements}

We would like to thank the family for their participation in the study and the two reviewers of our manuscript for their constructive comments that improved its quality.

\section{Funding}

This work is supported by a grant from Russian Commercial Bank (RCB).

\section{Availability of data and materials}

The data that support the findings of this study have been submitted to the European Nucleotide Archive (ENA) with accession number: PRJEB29481.

\section{Authors' contributions}

AK assisted in design of the study, carried out all the experiments and drafted the manuscript. EB assisted in the design of the study and edited the manuscript. KM performed analysis of the targeted sequencing data and edited the manuscript. MS diagnosed the patients and contributed to the writing of the case report. AM informed the patients and family members of the study and collected the samples and data. MAC contributed to study planning and revised the final manuscript. All authors read and approved the final manuscript.

\section{Ethics approval and consent to participate}

All research was approved by the Cyprus National Bioethics Committee ethics committee, protocol approval number EЕВK/EП/2014/32. All the participants have provided written informed consent.

\section{Consent for publication}

All participants signed informed consent for publication.

\section{Competing interests}

The authors declare that they have no competing interests.

\section{Publisher's Note}

Springer Nature remains neutral with regard to jurisdictional claims in published maps and institutional affiliations.

\section{Author details}

${ }^{1}$ Department of Cardiovascular Genetics and The Laboratory of Forensic Genetics, The Cyprus Institute of Neurology and Genetics, Nicosia, Cyprus. ${ }^{2}$ Cyprus School of Molecular Medicine, The Cyprus Institute of Neurology and Genetics, Nicosia, Cyprus. ${ }^{3}$ Department of Electron Microscopy/Molecular Pathology, The Cyprus Institute of Neurology and Genetics, Nicosia, Cyprus. ${ }^{4}$ American Medical Center, Nicosia, Cyprus.

Received: 27 July 2018 Accepted: 27 November 2018

Published online: 07 December 2018

\section{References}

1. Renard M, Callewaert B, Baetens M. Novel MYH11 and ACTA mutations reveal a role for enhanced TGF $\beta$ signaling in FTAAD. Int J Cardiol. 2013;165: 314-21.

2. Prakash S, Kuang SQ, Regalado E, Guo D, Milewicz D. Recurrent rare genomic copy number variants and bicuspid aortic valve are enriched in early onset thoracic aortic aneurysms and dissections. PLoS One. 2016;11:1-12.

3. Coady MA, Davies RR, Roberts M, Goldstein LJ, Rogalski MJ, Rizzo JA, et al. Familial patterns of thoracic aortic aneurysms. Arch Surg. 1999;134:361-7.

4. Wung S-F, Aouizerat BE. Newly mapped gene for thoracic aortic aneurysm and dissection. J Cardiovasc Nurs. 2004;19:409-16.

5. Kuzmik GA, Sang AX, Elefteriades JA. Natural history of thoracic aortic aneurysms. J Vasc Surg Elsevier Inc. 2012;56:565-71.

6. Albornoz G, Coady MA, Roberts M, Davies RR, Tranquilli M, Rizzo JA, et al. Familial thoracic aortic aneurysms and dissections-incidence, modes of inheritance, and Phenotypic Patterns. Ann Thorac Surg. 2006:82:1400-5.

7. De BJ, Campens L, De PA. Genes in thoracic aortic aneurysms/dissections do they matter? Ann Cardiothorac Surg. 2013;2:73-82.

8. Campens L, Callewaert B, Muiño Mosquera L, Renard M, Symoens S, De Paepe A, et al. Gene panel sequencing in heritable thoracic aortic disorders and related entities - results of comprehensive testing in a cohort of 264 patients. Orphanet J Rare Dis. 2015;10:1-9.

9. Poninska JK, Bilinska ZT, Franaszczyk M, Michalak E, Rydzanicz M, Szpakowski

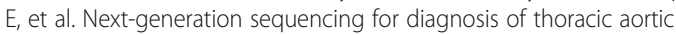
aneurysms and dissections: diagnostic yield, novel mutations and genotype phenotype correlations. J Transl Med BioMed Central. 2016;14:1-17.

10. Brownstein AJ, Kostiuk V, Ziganshin BA, Zafar MA, Kuivaniemi H, Body SC, et al. Genes associated with thoracic aortic aneurysm and dissection: 2018 update and clinical implications. Aorta. 2018:6:13-20.

11. Jondeau G, Boileau C. Familial thoracic aortic aneurysms. Curr Opin Cardiol. 2014:29:492-8.

12. Brownstein AJ, Ziganshin BA, Kuivaniemi H, Simon C, Bale AE, Elefteriades JA. Genes associated with thoracic aortic aneurysm and Dissection : an update and clinical implications. Aorta. 2017:5:11-20.

13. Gagnier JJ, Kienle G, Altman DG, Moher D, Sox H, Riley D, et al. The CARE guidelines: consensus-based clinical case reporting guideline development. Glob Adv Heal Med. 2013;2:38-43.

14. Wang K, Li M, Hakonarson HANNOVAR. Functional annotation of genetic variants from high-throughput sequencing data. Nucleic Acids Res. 2010:38:1-7.

15. Kumar P, Henikoff S, Ng PC. Predicting the effects of coding nonsynonymous variants on protein function using the SIFT algorithm. Nat Protoc. 2009:4:1073-82.

16. Adzhubei IA, Schmidt S, Peshkin L, Ramensky VE, Gerasimova A, Bork P, et al. A method and server for predicting damaging missense mutations. Nat Methods. 2010;7:248-9.

17. Schwarz JM, Cooper DN, Schuelke M, Seelow D. Mutationtaster2: mutation prediction for the deep-sequencing age. Nat Methods. 2014;11:361-2.

18. Choi $Y$, Chan AP. PROVEAN web server: a tool to predict the functional effect of amino acid substitutions and indels. Bioinformatics. 2015;31:2745-7. 
19. McLaren W, Gil L, Hunt SE, Riat HS, Ritchie GRS, Thormann A, et al. The Ensembl variant effect predictor. Genome Biol Genome Biology. 2016;17:1-14.

20. Zhang Y. I-TASSER: fully automated protein structure prediction in CASP8. Proteins. 2009;77:100-13.

21. Roy A, Yang J, Zhang YCOFACTOR. An accurate comparative algorithm for structure-based protein function annotation. Nucleic Acids Res. 2012; 40:471-7.

22. Yang J, Zhang Y. I-TASSER server: new development for protein structure and function predictions. Nucleic Acids Res. 2015;43:W174-81.

23. Richards S, Aziz N, Bale S, Bick D, Das S, Gastier-Foster J. Standards and Guidelines for the interpretation of sequence variants: a joint consensus recommendation of the American College of Medical Genetics and Genomics and the Association for Molecular Pathology. Genet Med. 2015; 17:405-24.

24. Verstraeten A, Luyckx I, Loeys B. Aetiology and management of hereditary aortopathy. Nat Rev Cardiol Nature Publishing Group. 2017;14:197-208.

25. Morisaki H, Akutsu K, Ogino H, Kondo N, Yamanaka I, Tsutsumi Y, et al. Mutation of ACTA2 gene as an important cause of familial and nonfamilial nonsyndromatic thoracic aortic aneurysm and/or dissection (TAAD). Hum Mutat. 2009:30:1406-11.

26. Guo DC, Pannu H, Tran-Fadulu V, Papke CL, Yu RK, Avidan N, et al. Mutations in smooth muscle a-actin (ACTA2) lead to thoracic aortic aneurysms and dissections. Nat Genet. 2007;39:1488-93.

27. Disabella E, Grasso M, Gambarin Fl, Narula N, Dore R, Favalli V, et al. Risk of dissection in thoracic aneurysms associated with mutations of smooth muscle alpha-actin 2 (ACTA2). Heart. 2011:97:321-6.

28. Hoffjan S, Waldmüller S, Blankenfeldt W, Kötting J, Gehle P, Binner P, et al. Three novel mutations in the ACTA2 gene in German patients with thoracic aortic aneurysms and dissections. Eur J Hum Genet. 2011;19:520-4.

29. Milewicz DM, Regalado E. Heritable thoracic aortic disease overview. In: GeneReviews ${ }^{\oplus} 2003$ [cited 14 Dec 2017]. p. 1-21.

30. Pannu H, Papke CL, Scherer S, Presley C, Guo D, Estrera AL, et al. MYH11 mutations result in a distinct vascular pathology driven by insulin-like growth factor 1 and angiotensin II. Hum Genet. 2007;16:2453-62.

31. Zhu L, Vranckx R, Van Kien PK, Lalande A, Boisset N, Mathieu F, et al. Mutations in myosin heavy chain 11 cause a syndrome associating thoracic aortic aneurysm/aortic dissection and patent ductus arteriosus. Nat Genet. 2006;38:343-9.

32. Zhu L, Bonnet D, Boussion M, Vedie B, Sidi D, Jeunemaitre X. Investigation of the MYH11 gene in sporadic patients with an isolated persistently patent arterial duct. Cardiol Young. 2007;17:666-72.

33. Guo DC, Papke CL, Tran-Fadulu V, Regalado ES, Avidan N, Johnson RJ, et al. Mutations in smooth muscle alpha-actin (ACTA2) cause coronary artery disease, stroke, and Moyamoya disease, along with thoracic aortic disease. Am J hum genet. The American society of. Hum Genet. 2009;84:617-27.

34. Bergeron SE, Wedemeyer EW, Lee R, Wen KK, McKane M, Pierick AR, et al. Allele-specific effects of thoracic aortic aneurysm and dissection a-smooth muscle actin mutations on actin function. J Biol Chem. 2011:286:11356-69.

35. Ke T, Han M, Zhao M, Wang QK, Zhang H, Zhao Y, et al. Alpha-actin-2 mutations in Chinese patients with a non-syndromatic thoracic aortic aneurysm. BMC med genet. BMC Medical Genetics. 2016;17:1-8.

36. Cooper K, Brown S. ACTA2 mutation and postpartum hemorrhage: A case report. BMC Med Genet. BMC Medical Genetics; 2017;18: 17-19.

37. Hannuksela M, Stattin E, Klar J, Ameur A, Johansson B, Sörensen K, et al. A novel variant in MYLK causes thoracic aortic dissections: genotypic and phenotypic description. BMC Med Genet. 2016;17:1-9.

Ready to submit your research? Choose BMC and benefit from:

- fast, convenient online submission

- thorough peer review by experienced researchers in your field

- rapid publication on acceptance

- support for research data, including large and complex data types

- gold Open Access which fosters wider collaboration and increased citations

- maximum visibility for your research: over $100 \mathrm{M}$ website views per year

At $\mathrm{BMC}$, research is always in progress.

Learn more biomedcentral.com/submissions 